\title{
Acetylcholine Turnover in an Autoactive Molluscan Neuron
}

\author{
Susan R. Barry ${ }^{1,2}$ and Alan Gelperin ${ }^{1,3}$ \\ Received July 18, 1983; revised October 24, 1983; accepted November 1, 1983 \\ KEY WORDS: acetylcholine release; acetylcholine turnover; acetylcholine pools; choline reuptake; autoac- \\ tive molluscan neuron; cholinergic synapse.
}

\section{SUMMARY}

1. We have studied acetylcholine $(\mathrm{ACh})$ turnover at the cholinergic synapse between an identified motoneuron, the salivary burster (SB), and the muscle cells of the salivary duct (SD) in the terrestrial mollusk Limax maximus.

2. Electrophysiological recordings were made of the $\mathrm{SB}$ action potentials and the SB-elicited junction potentials (JPs) on the SD. The amplitude of the JP was used as a measure of $\mathrm{ACh}$ release by the $\mathrm{SB}$.

3. The $\mathrm{SB}$ is an autoactive neuron that discharges 1 to 12 bursts of action potentials per min. During sustained bursting activity, the SB is able to maintain transmitter release for $18 \mathrm{hr}$ even in the absence of exogenous choline. The size of SB-elicited JPs does not vary during $18 \mathrm{hr}$ of activity. If the choline uptake blocker, hemicholinium-3 ( $\mathrm{HC}-3 ; 20 \mu M)$, is present in the saline, transmitter release and JP size are depressed by about $30 \%$ after $14 \mathrm{hr}$ of activity. Thus, the SB is partially dependent upon choline reuptake for maintained ACh synthesis and release.

4. In high $(9.45 \mathrm{~m} M)$-potassium $\left(\mathrm{K}^{+}\right)$saline, the SB fired tonically at twice its average spike frequency. JP amplitude initially increased, then declined to an amplitude which was $60 \%$ of the initial level. The addition of $20 \mu \mathrm{M} \mathrm{HC}-3$ to the high $-\mathrm{K}^{+}$saline caused a 75 to $100 \%$ decrease in JP size within $30 \mathrm{~min}$. Thus, during high-frequency tonic firing, the $\mathrm{SB}$ was primarily dependent on choline reuptake for ACh synthesis and release.

\footnotetext{
'Department of Biology, Princeton University, Princeton, New Jersey 08544.

${ }^{2}$ Present address: Department of Physiology, University of Michigan, Medical Science Building II, Ann Arbor, Michigan 48109.

${ }^{3}$ Department of Molecular Biophysics, Bell Laboratories, 600 Mountain Avenue, Murray Hill, New Jersey 07974, and Department of Biology, Princeton University, Princeton, New Jersey 08544.
} 
5. After JP size had been reduced in high- $\mathrm{K}^{+}$saline containing HC-3, the SB-SD synapse was returned to normal choline-free saline. The SB resumed bursting activity. JP amplitude gradually increased over the next $30 \mathrm{~min}$. Thus, high-frequency firing in HC-3 had not depleted the SB of its entire endogenous store of choline or ACh.

6. If the synapse was fatigued in high- $\mathrm{K}^{+}$saline containing $\mathrm{HC}-3$ and then placed in saline enriched with $300 \mu M$ choline, JP size increased within minutes. Thus, uptake of choline for $\mathrm{ACh}$ synthesis and release may be a more rapid process than mobilization of an endogenous transmitter store.

7. Finally, the SB-SD synapse was fatigued in high- $\mathrm{K}^{+}$saline containing $\mathrm{HC}-3$. HC-3 was then removed from the saline. The SB maintained high-frequency tonic activity. JP size did not increase unless choline was added to the saline.

8. We conclude that the SB possesses two releasable pools of $\mathrm{ACh}$, a "readily releasable" and a "reserve" transmitter store. The readily releasable pool is made up of ACh newly synthesized from choline taken up from the saline. During high-frequency firing, the SB discharges all ACh from this store. During normal bursting activity, the $\mathrm{SB}$ may discharge $\mathrm{ACh}$ from both the readily releasable and the reserve transmitter pool. The proportion of $\mathrm{ACh}$ released from each pool may vary with the total transmitter stores and the spiking activity of the SB neuron.

\section{INTRODUCTION}

Dietary administration of choline elevates the choline levels in the blood and cerebrospinal fluid. This increase in exogenous choline may stimulate choline uptake, acetylcholine $(\mathrm{ACh})$ synthesis, and $\mathrm{ACh}$ release by cholinergic neurons (Cohen and Wurtman, 1976; Ulus et al., 1977). To determine the effects of exogenous choline on transmitter output, one must investigate $\mathrm{ACh}$ turnover within cholinergic nerve terminals. For example, if neurons maintain a large reserve transmitter supply, variations in exogenous choline may have little effect on $\mathrm{ACh}$ content or output. If, however, the cells discharge transmitter that, in large part, has been newly synthesized from exogenous precursor, fluctuations in external choline levels may produce large changes in ACh synthesis and release.

We have studied $\mathrm{ACh}$ turnover at a cholinergic synapse between an identified motoneuron, the salivary burster (SB), and the muscle cells of the salivary duct (SD) in the mollusk, Limax maximus. Previous work has shown that an elevation in exogenous choline enhances transmission at this synapse probably by increasing ACh synthesis and release by the presynaptic terminals of the SB (Barry and Gelperin, 1982a). In this paper we present evidence that the SB possesses at least two releasable pools of ACh. The magnitude and time course of choline's action at the synapse may depend upon the differing contributions of the two $\mathrm{ACh}$ pools to transmitter output. The proportion of $\mathrm{ACh}$ released from each pool varies in turn with the total transmitter stores and the spiking activity of the SB neuron.

\section{METHODS}

Physiological recordings were made as described in previous papers (Barry and Gelperin, 1982a,b). Briefly, the cerebral and buccal ganglia and the attached salivary 
ducts (SDs) and salivary nerves (SNs) were removed from 5- to 15-g slugs (Limax maximus) and pinned out in a Sylgard-lined petri dish. Spontaneous activity of the SB neuron was recorded with a suction electrode on the salivary nerve, while junction potentials (JPs) were recorded with focal suction electrodes on the SD (Fig. 1). Extracellular recordings were amplified, displayed on an oscilloscope, and filmed with a Grass kymograph camera. Experiments were performed at $20^{\circ} \mathrm{C}$ using a Peltier refrigeration device to maintain a constant temperature.

The amplitudes of JPs were determined from the photographic records by measuring the distance from the baseline to the peak of a JP. When the SB discharged bursts of spikes, only the first JPs following the first spikes in each burst were used for

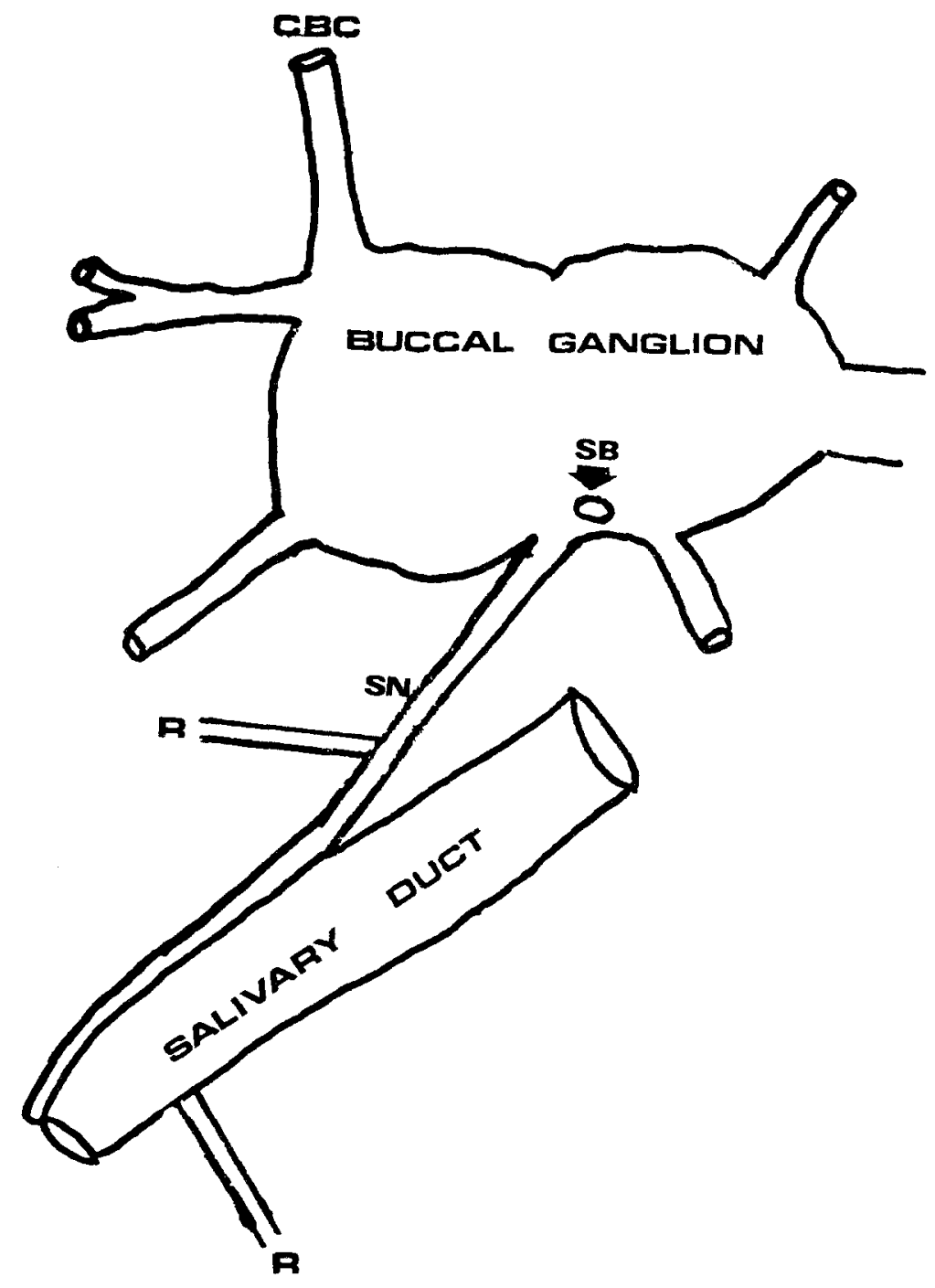

Fig. 1. Schematic diagram of the isolated buccal ganglion and attached salivary duct. $\mathrm{CBC}$, cerebrobuccal connective; $\mathrm{SB}$, salivary burster; $\mathrm{SN}$, salivary nerve; $\mathrm{R}$, recording electrode. 
statistical analysis. The sizes of JPs occurring under different conditions in the same preparation were compared using Student's $t$ test for matched pairs.

Normal saline contained $55.4 \mathrm{~m} M \mathrm{Na}^{+}, 4.2 \mathrm{mM} \mathrm{K} \mathrm{K}^{+}, 7.0 \mathrm{mM} \mathrm{Ca}{ }^{2+}, 4.6 \mathrm{~m} M$ $\mathrm{Mg}^{2+}, 80.1 \mathrm{~m} M \mathrm{Cl}^{-}, 0.2 \mathrm{mM} \mathrm{\textrm {H } _ { 2 }} \mathrm{PO}_{4}{ }^{+}, 2.5 \mathrm{~m} M \mathrm{HCO}_{3}^{-}$, and $5.0 \mathrm{~m} M$ dextrose. Choline chloride and hemicholinium-3 were obtained from Sigma Chemical Company. Solutions were made fresh for each experiment.

\section{RESULTS}

The SB neuron is located in the buccal ganglion (Prior and Gelperin, 1977). It sends its axon down the SN to make monosynaptic connections with the muscle cells of the SD (Beltz and Gelperin, 1980; Barry and Gelperin, 1982a). Each SB spike is followed by a JP recorded from the SD. Previous experiments have shown that the amplitude of SB evoked JPs can be used as a measure of the amount of ACh released by the SB (Barry and Gelperin, 1982a).

When the SB-SD synapse is isolated in physiological saline, the SB will continue to discharge 1-20 bursts of action potentials per min for several days. During 17 to 18 $\mathrm{hr}$ of bursting activity, the amplitudes of SB evoked JPs change by an average of only $13 \pm 8 \%$ when the isolated synapse is incubated in saline containing no choline (see Fig. 5, Barry and Gelperin, 1982a). Thus, during sustained activity, the SB is able to maintain transmitter release even in the absence of exogenous choline. Either the SB possesses such a large transmitter supply that the amount of $\mathrm{ACh}$ released per action potential is only a very small fraction of the amount stored or released transmitter is continually replaced by newly synthesized or newly mobilized $\mathrm{ACh}$.

When ACh is released, it is hydrolyzed into choline and acetate. If choline is recaptured by the $\mathrm{SB}$ nerve terminals and reused for $\mathrm{ACh}$ synthesis and release, transmission at the SB-SD synapse should be reduced by blocking choline reuptake. To test the dependence of the SB on choline reuptake for continued transmitter release, the synapse was incubated in 10 or $20 \mu M$ hemicholinium-3 (HC-3). This concentration of HC-3 can block choline reuptake by up to $90 \%$ (Osborne, 1976). HC-3 had no immediate effect on the amplitude of SB-elicited JPs. However, JPs decreased in size after many hours in HC-3. In one experiment after $14 \mathrm{hr}$ of bursting activity in $20 \mu \mathrm{M}$ HC-3, the amplitude of the first JP in each burst fell from 10.4 to $7.3 \mathrm{mV}$, or by $31 \%$ $(P<0.005)$ (Fig. 2). In a second experiment, the average size of the first JP in each burst decreased from 6.2 to $3.8 \mathrm{mV}$, or by $38.7 \%(P<0.001)$, after $20 \mathrm{hr}$ of SB activity in $20 \mu M \mathrm{HC}-3$. In a third experiment, JP size was reduced from 10.5 to $8.1 \mathrm{mV}$, or $23 \%(P<0.01)$, after $16 \mathrm{hr}$ in $10 \mu M \mathrm{HC}-3$.

If the action potential frequency of the SB was increased, the effect of HC-3 on JP size developed more rapidly. An increase in the $\mathrm{K}^{+}$concentration in the saline from 4.2 to $9.45 \mathrm{~m} M$ depolarized the SB and caused it to switch from a bursting to tonic mode of firing. The action potential frequency in high $\mathrm{K}^{+}$saline averaged 5 to 8 spikes per sec, depending on the preparation. This spike rate was about double the net spike frequency of the SB during bursting activity in normal saline. For example, in the experiment illustrated in Fig. 3, the SB discharged a burst of 9 to 10 spikes every 2.5 to $3 \mathrm{sec}$, or an average of 3 to 4 spikes per sec. In high- $\mathrm{K}^{+}$saline, the same neuron fired tonically at a maximum frequency of 7.2 spikes per sec, or twice the net spike frequency observed 

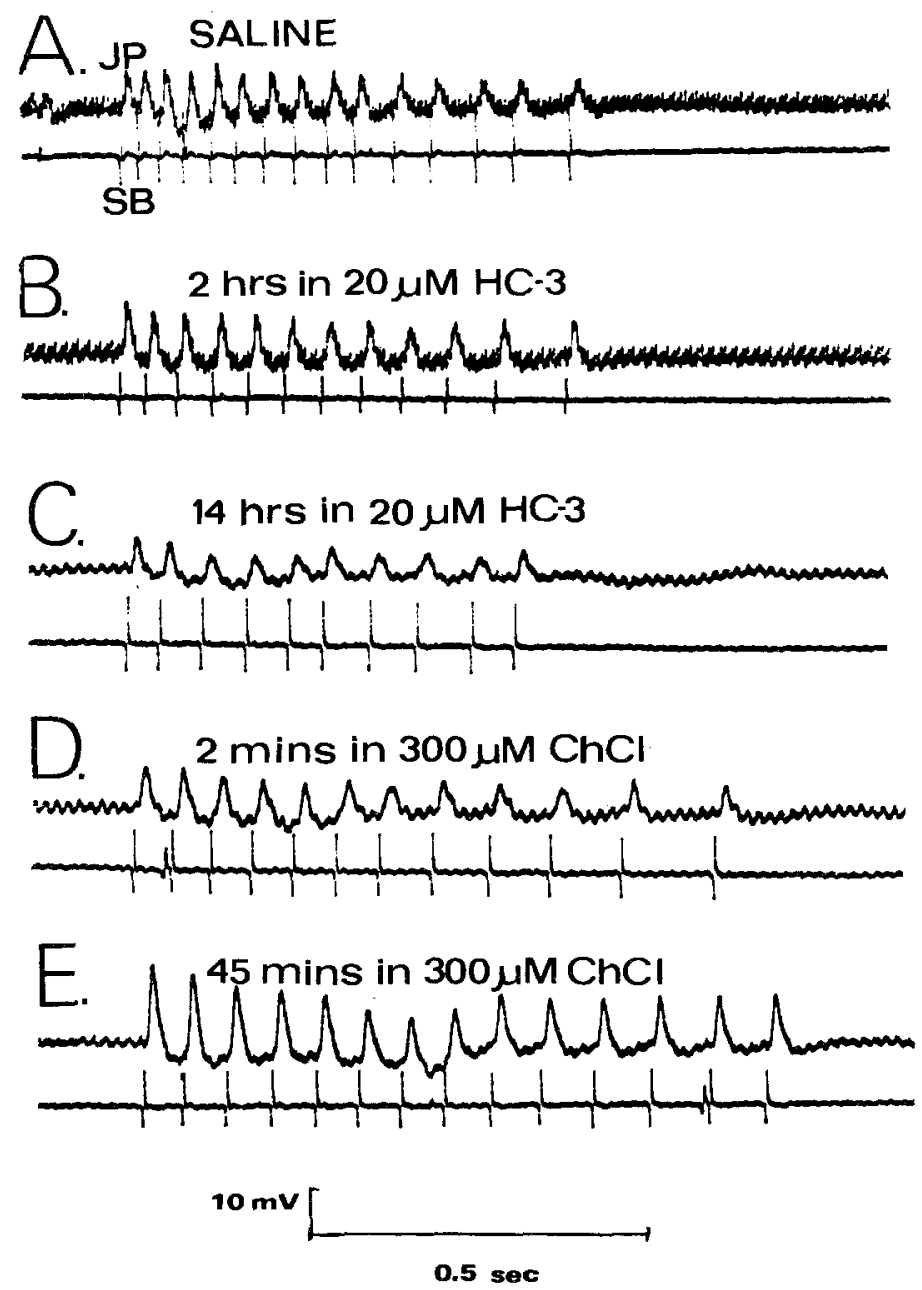

Fig. 2. Junction potential amplitude decreased by $31 \%$ after incubation in saline containing $20 \mu M$ hemicholinium-3. Spontaneous activity of the SB and corresponding JPs on the SD are shown (A) in saline, (B) after $2 \mathrm{hr}$ of incubation in $20 \mu M \mathrm{HC}-3$, and (C) after $14 \mathrm{hr}$ in $20 \mu M \mathrm{HC}-3$. During this period, JP amplitude decreased by $31 \%$. Removal of $\mathrm{HC}-3$ and addition of choline chloride to the saline bath produced a rapid increase in JP amplitude. SB spikes and JPs were recorded after (D) 2 min and (E) 45 min of incubation in saline free of $\mathrm{HC}-3$ and enriched with $300 \mu M$ choline chloride. JP, junction potential; SB, salivary burster; $\mathrm{HC}-3$, hemicholinium-3; $\mathrm{ChCl}$, choline chloride.

during bursting activity. During prolonged tonic firing in high- $\mathrm{K}^{+}$saline, JPs initially increased, then declined and stabilized at an amplitude which was about $60 \%$ of the initial level. If $20 \mu M \mathrm{HC}-3$ was present in the high- $\mathrm{K}^{+}$saline, JP amplitude fell more rapidly. After 15 to $30 \mathrm{~min}$, JPs had either disappeared or declined to a steady-state level which was less than $25 \%$ of the initial amplitude (Figs. 3 and 4 ).

In one preparation, while bathed in normal- $\mathrm{K}^{+}$saline, the $\mathrm{SB}$ was spontaneously firing at the unusually rapid rate of 40 bursts of 10 to 12 spikes per min, or an average 

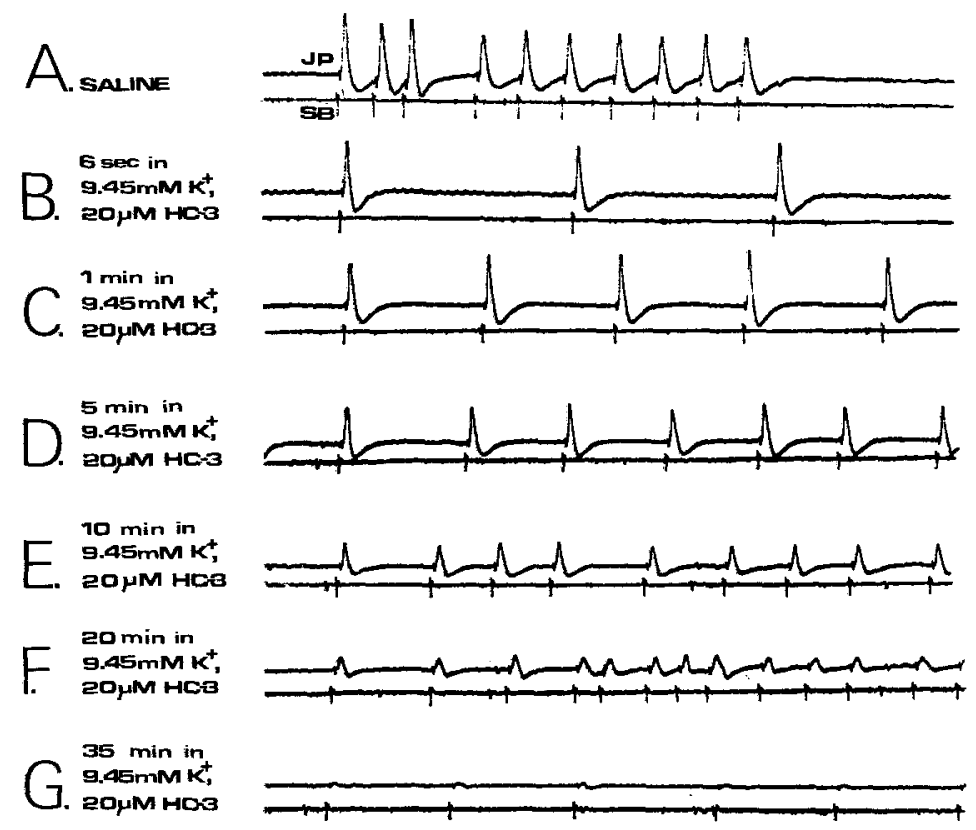

125 Eec in

1. 300,M che

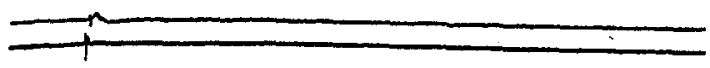

3 min in

300 Min cha

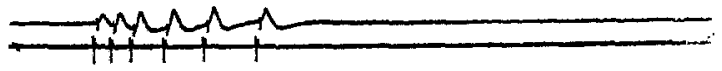

$\int \begin{aligned} & 10 \mathrm{~min} \text { in } \\ & 300 \mu \mathrm{M} \text { Chci }\end{aligned}$

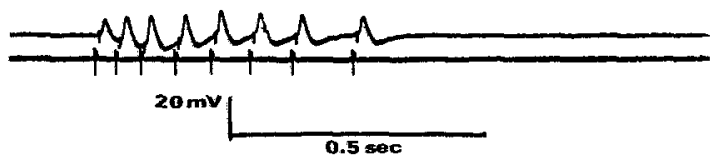

Fig. 3. A rapid decrease in JP amplitude was seen in high- $\mathrm{K}^{+}$saline containing $\mathrm{HC}-3$. An increase in $\mathrm{K}^{+}$concentration in the saline from 4.2 to $9.45 \mathrm{mM}$ depolarized the SB and caused it to fire tonically. When $20 \mu M \mathrm{HC}-3$ was added, the amplitude of JPS on the SD fell rapidly. In A, the spontaneous activity of the SB and the corresponding JPs on the SD were recorded in normal saline. This trace represents one SB burst. The next burst followed $2.5 \mathrm{sec}$ later. In B-G, tonic spiking of the SB and decreasing JPs were seen in high- $\mathrm{K}^{+}$saline containing $\mathrm{HC}-3$. After $35 \mathrm{~min}$, the $\mathrm{SB}$ was placed in normal saline containing $300 \mu \mathrm{M}$ choline chloride $(\mathbf{H}-\mathbf{J})$. The $\mathrm{SB}$ resumed bursting activity and JP amplitude increased within 3 min. JP, junction potential; SB, salivary burster; HC-3, hemicholinium-3; $\mathrm{ChCl}$, choline chloride.

of 7 spikes per sec. At this synapse, as at synapses exposed to high- $\mathrm{K}^{+}$saline, $\mathrm{HC}-3$ produced a rapid reduction in JP size. HC-3 $(10 \mu M)$ caused JPs to decrease from 16.1 to $3.6 \mathrm{mV}$, or by $71 \%$, in only $9 \mathrm{~min}$ (see Fig. 10, Barry and Gelperin, 1982a).

In $9.45 \mathrm{mM} \mathrm{K}^{+}$saline containing HC-3, JP amplitude decreased exponentially until a steady-state size was reached. If the natural $\log$ of the instantaneous JP size 


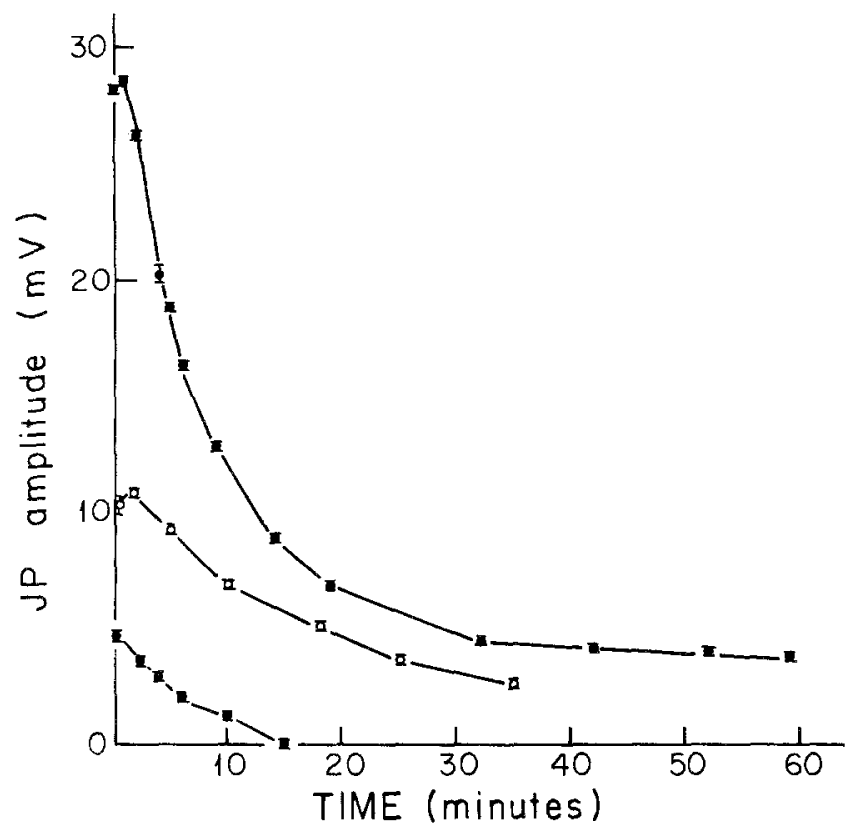

Fig. 4. The decrease in JP amplitude in bigh- $\mathrm{K}^{+}$saline containing 20 $\mu M \mathrm{HC}-3$ is plotted for three experiments. For each point, the sizes of JPs occurring over a 5-sec time span were averaged. Error bars indicate standard errors of the means.

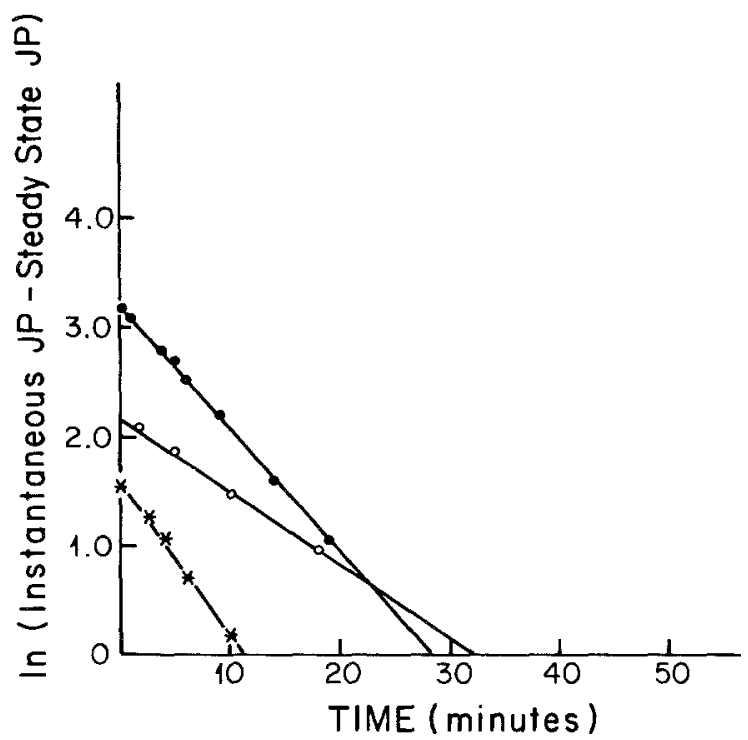

Fig. 5. When the SB fired tonically in high- $\mathrm{K}^{+}$saline containing $20 \mu M \mathrm{HC}-3$, JP amplitude declined as a single exponential. For the three experiments illustrated in Fig. 4, the steady-state JP size was subtracted from the instantaneous JP amplitude, and the natural log of this difference was calculated and plotted. A straight line was obtained indicating an exponential decrease. To determine the instantaneous JP size, the amplitudes of JPs occurring over a 5-sec interval were averaged. $J P_{s}$ reached a steady-state size after $30 \mathrm{~min}(\mathrm{~A}$, after $20 \mathrm{~min}(\mathrm{~B}, \mathrm{O}-\mathrm{O})$, and after $15 \mathrm{~min}\left(\mathrm{C}, *--_{*}\right)$. 
minus the steady-state JP size was plotted against time, a straight line was obtained. Since the points fell along one straight line, the process of transmitter depletion can be described by a single exponential (Fig. 5). To show linearity, the Pearson productmoment correlation coefficients were calculated for the three experiments shown in Fig. 5. Correlation coefficients were 0.87 for $\mathrm{A}, 0.75$ for B, and 0.80 for C.

In high- $\mathrm{K}^{+}$saline containing HC-3, JPs either disappeared or decreased to less than $25 \%$ of their initial value. When the synapse, thus fatigued, was placed in normal saline enriched with $300 \mu M$ choline, the SB resumed its normal bursting activity, and JP amplitude increased within 3 min (Fig. 6).

Recovery of JPs also occurred when the fatigued SB-SD synapse was placed in normal saline containing no choline. However, the increase in JP amplitude developed more slowly in choline-free than in choline-enriched saline. In choline-free saline, no change in JP amplitude was observed within the first $5 \mathrm{~min}$. Instead, a slow increase in JP size occurred over the next 30 min (Fig. 6).

Recovery of JPs even occurred when the fatigued synapse was placed in normal saline containing HC-3. The presence of HC-3 prevented uptake of any exogenous

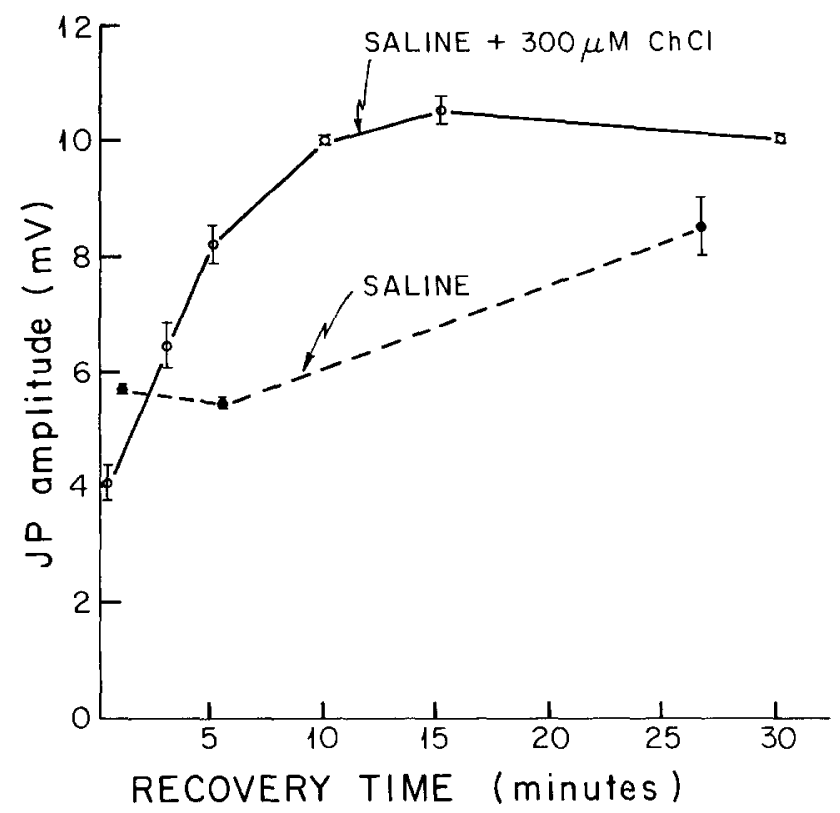

Fig. 6. Recovery of JP amplitude was more rapid in choline-enriched saline than in normal saline. By depolarizing the $\mathrm{SB}$ in high- $\mathrm{K}^{+}$saline containing $20 \mu M \mathrm{HC}-3$, the amplitude of JPs on the SD fell from 28 to $4 \mathrm{mV}(86 \%)$ within $35 \mathrm{~min}$. The cell was then placed in saline enriched with $300 \mu M$ choline chloride and the normal $\mathrm{K}^{+}$concentration. During the next half-hour, an increase in JP amplitude was observed. Again, the SB was depolarized in the presence of $\mathrm{HC}-3$ and a rapid decrease in JP size was seen. The cell was then placed in normal saline containing no choline. Again, JPs increased, but this recovery was not as rapid as that observed in the presence of $300 \mu M$ choline. This figure is a plot of the change in average amplitude of the first JPs per four bursts in the presence and absence of $300 \mu M$ choline. Values for standard errors of the means are indicated by the error bars. 
choline that may have been present and ensured that all of the $\mathrm{ACh}$ released by the SB derived from endogenous stores. In two preparations, the SB was depleted of transmitter in high- $\mathrm{K}^{+}$saline containing $20 \mu M \mathrm{HC}-3$. The synapse was then placed in normal saline containing $20 \mu M$ HC-3. JP amplitude increased initially but, after 60 min, declined (Fig. 7).

No recovery of JPs occurred if the depleted SB continued rapid tonic activity in high- $\mathrm{K}^{+}$choline-free saline. For example, the SB-SD synapse was placed in high-K $\mathrm{K}^{+}$ saline containing $20 \mu \mathrm{M} \mathrm{HC}-3$. After $15 \mathrm{~min}$ of tonic firing, JPs decreased from 4.7 to less than $1 \mathrm{mV}$. The synapse was then washed twice with normal saline. During this time, JP amplitude increased to $2 \mathrm{mV}$. The SB-SD junction was then placed in high- $\mathrm{K}^{+}$saline containing no HC-3. The SB continued to fire tonically. JPs declined and disappeared within $10 \mathrm{~min}$. The synapse was then placed in high- $\mathrm{K}^{+}$saline containing 10 or $50 \mu \mathrm{M}$ choline chloride. The SB maintained tonic activity. Within 60 $\mathrm{sec}$, JP amplitude increased. After only $5 \mathrm{~min}$ in high- $\mathrm{K}^{+}$saline containing $50 \mu \mathrm{M}$ choline, JP amplitude had exceeded its initial value (Fig. 8).

Thus, recovery of JP size at the fatigued SB-SD synapse depended upon both the action potential frequency of the SB and the concentration of choline in the saline. In high-K $\mathrm{K}^{+}, \mathrm{HC}-3$ saline, the SB depolarized and fired tonically at a spike rate about twice that observed in normal saline. JPs decreased rapidly and, after $30 \mathrm{~min}$, either disappeared or reached a steady-state amplitude which was less than $25 \%$ of their initial size. When the $\mathrm{K}^{+}$concentration in the saline was lowered to its normal level,

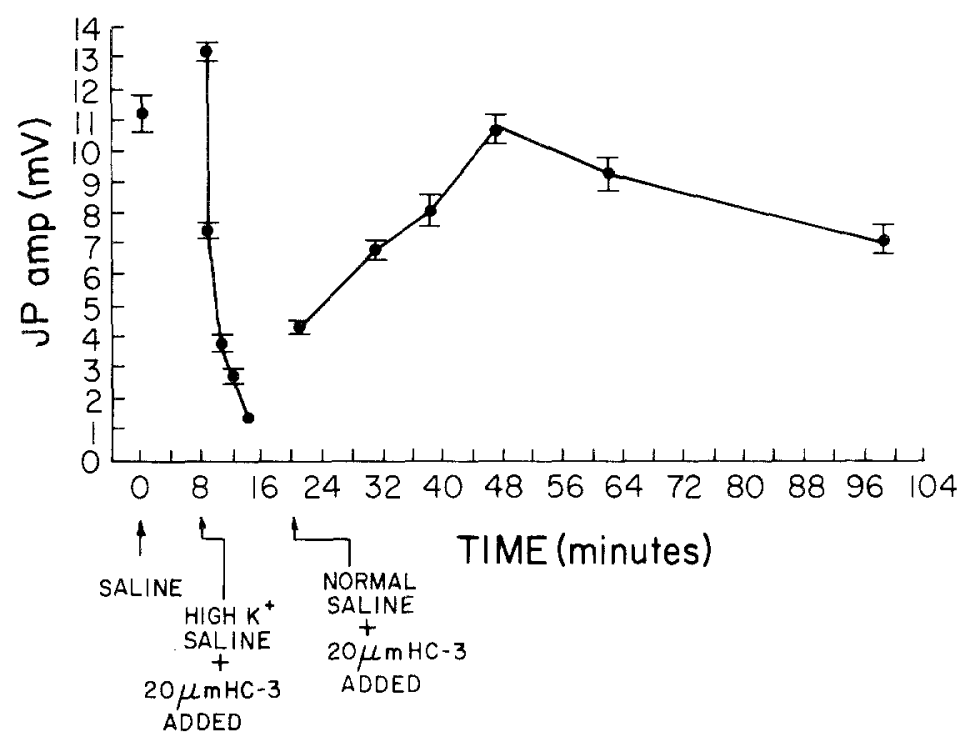

Fig. 7. Recovery of JP amplitude occurred in $20 \mu M$ HC-3. JP size was reduced by increased SB activity in high- $\mathrm{K}^{+}$saline containing $\mathrm{HC}-3$. The preparation was then placed in normal saline to which $20 \mu M \mathrm{HC}-3$ had been added. JP amplitude increased initially but, after $60 \mathrm{~min}$, declined. During tonic activity in high-K $\mathrm{K}^{+}$ saline containing $\mathrm{HC}-3$, the sizes of JPs occurring over a 5 -sec interval were averaged. During bursting activity in normal saline with $\mathrm{HC}-3$, the amplitudes of the first JPs per five bursts were averaged. Error bars indicate standard errors of the means. 


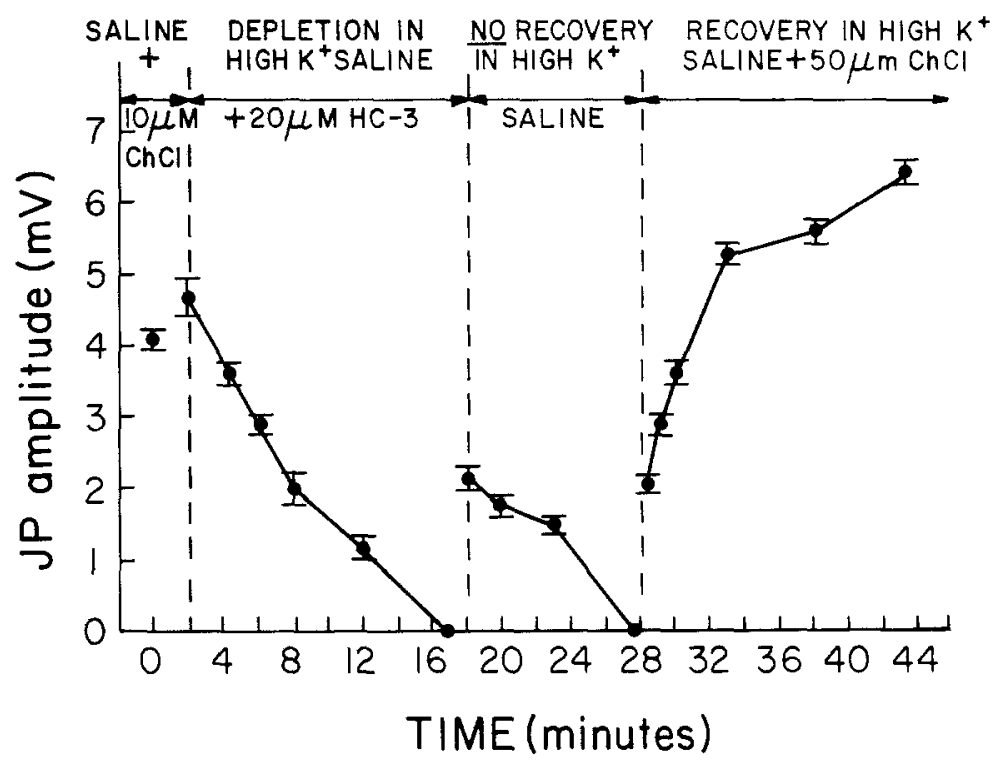

Fig. 8. Recovery of JPs during tonic activity in high-K $\mathrm{K}^{+}$saline occurred only if choline was present. JP amplitude was reduced by increased SB activity in high-K $\mathrm{K}^{+}$saline containing $20 \mu M$ HC-3. The synapse was then washed twice with normal saline. During this time, the SB was silent. When the cell was placed in high- $\mathrm{K}^{+}$saline free of $\mathrm{HC}-3$, an initial increase in JP size was followed by decline and disappearance of the JPs. If $50 \mu M$ choline chloride was then added to the high-K $\mathrm{K}^{+}$saline, JP size increased within the first minute and exceeded its initial value within $5 \mathrm{~min}$. Throughout this experiment, the SB fired tonically at an average rate of 7 spikes per sec. JPs occurring within a 5 -sec interval were averaged. Error bars indicate standard errors of the means.

the SB resumed its bursting activity, and JP amplitude gradually increased even in the absence of exogenous choline. HC-3 only partially blocked this recovery. In normal saline containing $20 \mu M \mathrm{HC}-3$, JPs initially increased but, after an hour, declined. If the SB, depleted of transmitter, continued rapid tonic activity, however, JP size did not recover unless choline was added to the saline.

\section{DISCUSSION}

The SB, an autoactive bursting neuron, was able to maintain ACh release over long periods of time even in the absence of exogenous choline. For example, SB-elicited JPs varied by only $13 \%$ after $18 \mathrm{hr}$ of continuous activity in choline-free saline. However, when choline reuptake was blocked with 10 or $20 \mu M$ HC-3, JP amplitude declined by more than $30 \%$ after 14 to $20 \mathrm{hr}$ of normal bursting activity. Uptake of choline by the SB is necessary for maintained ACh synthesis and release. As the SB continued to secrete $\mathrm{ACh}$ in the presence of $\mathrm{HC}-3, \mathrm{ACh}$ stores were depleted. Transmitter release and JP size decreased with diminishing transmitter stores. Since JP amplitude and transmitter release were depressed in $\mathrm{HC}-3$, a proportion of the released transmitter probably represented $\mathrm{ACh}$ that was newly synthesized from 
recaptured choline. Since transmitter output was not totally eliminated, some $\mathrm{ACh}$ must have been mobilized or released from an endogenous reserve transmitter store.

Further experiments, described here, suggest that ACh synthesized from recaptured choline was immediately and preferentially released. This ACh makes up a "readily releasable" pool. During high-frequency firing, the SB may discharge most if not all transmitter from this pool. In addition, the SB may possess a "reserve" pool of $\mathrm{ACh}$ that is mobilized for release more gradually. During normal bursting activity, both the readily releasable and the reserve $\mathrm{ACh}$ pools may contribute to transmitter release.

The effect of HC-3 on JP size developed more rapidly at a very active synapse. In high- $\mathrm{K}^{+}$saline, which caused a doubling in the SB firing rate, $\mathrm{HC}-3$ depressed JP size in minutes. In contrast, during bursting activity in normal saline, the effect of HC-3 developed only after several hours. At high firing frequencies, therefore, the SB may have been more dependent on choline reuptake for continued $\mathrm{ACh}$ synthesis and release.

After exposure to high- $\mathrm{K}^{+}$saline containing $\mathrm{HC}-3$, the $\mathrm{SB}$ may have been depleted of its readily releasable transmitter pool. JPs were reduced or eliminated. However, the SB was not depleted of its entire ACh store. When the synapse was placed in normal choline-free saline, JP size increased over the next $30 \mathrm{~min}$. This gradual recovery in JP amplitude occurred in choline-free saline, probably because the $\mathrm{SB}$ mobilized $\mathrm{ACh}$ from an endogenous reserve pool. When the neuron was spiking rapidly in high- $\mathrm{K}^{+}$saline, this reserve transmitter pool may have been mobilized too slowly to keep pace with transmitter release.

Recovery of JP size after high-frequency depletion also occurred in normal saline containing HC-3. JPs initially increased but, after $60 \mathrm{~min}$, declined. The presence of hemicholinium prevented reuptake of released choline. Therefore, all $\mathrm{ACh}$ that was released was derived from an endogenous store. Since JPs recovered, the SB apparently mobilized a reserve transmitter store which could support release at a low frequency but not during high-frequency activity. Since ACh output and JP amplitude declined after $60 \mathrm{~min}$ of low-frequency activity in HC-3, even the reserve pool was depleted by this time.

Recovery of JP amplitude after high-frequency depletion occurred more rapidly in choline-enriched than in normal saline. Choline in the bath was probably taken up by the SB for ACh synthesis and release. Since recovery of JP size occurred more rapidly in choline-enriched than choline-free saline, uptake of exogenous choline for transmitter synthesis and release may be a more rapid process than mobilization of an endogenous store. To test this further, the SB-SD synapse was first fatigued in high- $\mathrm{K}^{+}$saline containing $20 \mu M$ HC-3. HC-3 was then removed from the high- $\mathrm{K}^{+}$ saline. The SB continued tonic firing. No recovery of JPs occurred unless choline was added to the saline.

When the SB was spiking tonically in high $\mathrm{K}^{+}$, choline-free saline, mobilization of a reserve transmitter pool may have been too slow to keep pace with transmitter release. Thus, no recovery of JP size was observed. If choline was present in the saline, however, the $\mathrm{SB}$ was able to recapture choline and resynthesize $\mathrm{ACh}$ for immediate release. Thus, the SB may depend for $\mathrm{ACh}$ output on both uptake of exogenous and released choline and mobilization of endogenous stores. Choline taken up by the nerve 
terminals may be converted to ACh that is immediately and preferentially released. This ACh makes up a readily releasable pool. An endogenous reserve pool of ACh may be mobilized more gradually.

When the SB depolarized and fired tonically in high- $\mathrm{K}^{+}$saline containing $\mathrm{HC}-3$, JP size declined exponentially until a steady-state amplitude was reached. Since JPs decreased as a single exponential, a constant fraction of the available $\mathrm{ACh}$ store was probably released with each impulse. Since a constant fraction of transmitter was released, $\mathrm{ACh}$ was probably discharged from a single store, the readily releasable store. As this store was depleted, the amount of $\mathrm{ACh}$ released with each spike diminished as well. Bennett and McLachlan, (1972a) studied ACh release from the guinea pig superior cervical ganglion. Prolonged repetitive stimulation in the presence of $\mathrm{HC}-3$ led to an exponential decline in $\mathrm{ACh}$ output. They concluded that ACh was discharged, during high-frequency stimulation, from a single store in the preganglionic nerve terminals.

Presently, there are no anatomical correlates for the proposed readily releasable and reserve transmitter pools in the SB. Beltz and Gelperin (1979) have reported the presence of synaptic vesicles in axonal branches from the salivary nerves at areas of close contact with the salivary duct. These could be SB nerve terminals. If $\mathrm{ACh}$ is discharged from the $\mathrm{SB}$ in vesicles, the readily releasable pool may represent transmitter packaged in vesicles located at the release sites, while the reserve pool may represent nonvesicular $\mathrm{ACh}$ or $\mathrm{ACh}$ stored in vesicles situated further from the terminals.

ACh turnover in the SB was studied during bursting activity in normal saline and during high-frequency tonic acitvity in high- $\mathrm{K}^{+}$medium. High $\mathrm{K}^{+}$concentrations not only accelerated the SB firing rate but also changed the neuron's spiking pattern from bursting to tonic. In addition, high $\mathrm{K}^{+}$may depolarize the $\mathrm{SD}$ muscle. It is possible that the effects of high $\mathrm{K}^{+}$on JP size resulted not only from the increased SB impulse rate but also from the change in SB firing pattern or from direct membrane effects on the $\mathrm{SD}$. In one preparation, while in normal saline, the burst frequency of the SB was two to four times that observed in all other preparations. At this unusually active synapse, the addition of $10 \mu M$ HC-3 reduced JP size by $71 \%$ within 9 min. When HC-3 was removed and $100 \mu M$ choline added to the depleted synapse, JP size doubled within 9 min (see Fig. 10, Barry and Gelperin, 1982a). This synapse, which was bursting at an accelerated frequency, responded to $\mathrm{HC}-3$ and choline in a similar manner as synapses which were tonically active in high- $\mathrm{K}^{+}$saline. Thus, the effects of high $\mathrm{K}^{+}$on $\mathrm{ACh}$ turnover in the SB may result primarily from its actions on SB spike frequency and not from its effect on the SB firing pattern or from possible effects on the membrane potential of the SD. However, the role of bursting or tonic activity on ACh turnover will best be studied by impaling the SB and directly controlling its firing rate and pattern of discharge.

The relationship of $\mathrm{ACh}$ output to neuronal activity has been studied in several vertebrate preparations. Birks and MacIntosh (1961) demonstrated that ACh release is coupled to synthesis in the preganglionic cells of the cat superior cervical ganglion. During physiological activity, the preganglionic neurons discharge more ACh than is originally present in the ganglion. Yet, an active ganglion maintains the same transmitter content as a resting ganglion provided that an external source of choline is available. In the presence of the choline uptake inhibitor, $\mathrm{HC}-3$, however, the active 
ganglion is not able to maintian its ACh supply. During neuronal activity, therefore, exogenous choline is taken up by the preganglionic nerve cells and used for $\mathrm{ACh}$ synthesis and release.

$\mathrm{ACh}$ turnover has also been studied at the frog neuromuscular junction, mouse and rat phrenic nerve-diaphragm junctions, and sympathetic ganglia of the rat and guinea pig. During high-frequency neuronal activity, these tissues are able to maintain high levels of transmitter output by increased production of $\mathrm{ACh}$ (Ceccarelli et al., 1973; Ceccarelli and Hurlbut, 1975; Gorio et al., 1978; Potter, 1970; Sacchi and Perri, 1973; Bennett and McLachlan, 1972a,b).

Our experiments indicate that choline taken up by the SB nerve terminals is converted to $\mathrm{ACh}$ for immediate and preferential release. Similar results have been found in several vertebrate preparations. During high-frequency firing of the preganglionic neurons of the cat superior cervical ganglion, newly synthesized transmitter is preferentially released. These neurons were loaded with tritiated ACh until 80 to $85 \%$ of the $\mathrm{ACh}$ in the terminals was radiolabeled. During continual stimulation in the presence of acetyl-CoA and nonradioactive choline, less than $50 \%$ of the transmitter released was tritiated. Thus, most of the synaptically secreted ACh was synthesized during stimulation from precursors in the saline (Collier, 1969). Newly synthesized $\mathrm{ACh}$ is also preferentially released from the rat phrenic nerve-diaphragm junction (Potter, 1970).

High-affinity choline uptake may be regulated by neuronal spiking activity. Neuronal stimulation enhances choline uptake into the cat sympathetic ganglion (Collier and Katz, 1974; Collier and Ilson, 1977). Depolarization does not affect choline uptake into the abdominal ganglion of Aplysia (Eisenstadt et al., 1975) but does increase high-affinity uptake into rat brain hippocampal synaptosomes (Murrin and Kuhar, 1976; Murrin et al., 1977).

Since choline uptake and $\mathrm{ACh}$ synthesis may be enhanced by neuronal activity, the action of choline on a nervous system may depend upon what synapses are active during application of the precursor. Thus, an increase in circulating choline levels may influence $\mathrm{ACh}$ content and release only at nerve terminals which are rapidly turning over transmitter.

As reported in previous papers (Barry and Gelperin, 1982a,b), incubation of the unstimulated but spontaneously active SB-SD synapse in choline-enriched saline is followed, after 3 to $6 \mathrm{hr}$, by a 40 to $200 \%$ increase in JP amplitude. This change in synaptic potential size is blocked by $\mathrm{HC}-3$ and, therefore, probably results from an increase in choline uptake, ACh synthesis, and ACh release. When the SB is depleted of transmitter in high- $\mathrm{K}^{+}$saline containing $\mathrm{HC}-3$, exposure to choline results in an immediate increase in JP size. The existence of two ACh pools in the SB may explain the difference in time course of choline's effect on JP size at high-frequency depleted and at nondepleted junctions. Prolonged high-frequency firing of the SB-SD synapse in high- $\mathrm{K}^{+}$saline containing $\mathrm{HC}-3$ may deplete the nerve terminals of readily releasable $\mathrm{ACh}$. The readily releasable transmitter pool is highly dependent on exogenous choline for $\mathrm{ACh}$ resynthesis and release. During rapid tonic firing, recycled $\mathrm{ACh}$ from the readily releasable pool is preferentially released, thus rendering the synapse particularly sensitive to the exogenous choline levels. The size of the reserve $\mathrm{ACh}$ pool is less dependent upon external choline concentrations. During normal activity, the nondepleted SB neuron may discharge a greater proportion of $\mathrm{ACh}$ from 
this endogenous reserve store than during tonic activity in high- $\mathrm{K}^{+}$saline. Thus, in normal saline, choline's effect develops more slowly. The magnitude and time course of choline's action at the synapse may depend upon the differing contributions of the two $\mathrm{ACh}$ pools to transmitter output, a process which in turn depends upon the action potential frequency of the presynaptic cell.

\section{ACKNOWLEDGMENTS}

This work was supported by NIH Grant NSMH15698 and NSF Grant BNS8005822 to A.G. and NSF Predoctoral Fellowship, NIH Traineeship MH15799, and ALS Postdoctoral Fellowship to S.R.B.

\section{REFERENCES}

Barry, S. R., and Gelperin, A. (1982a). Exogenous choline augments transmission at an identified cholinergic synapse in terrestrial mollusk Limax maximus. J. Neurophysiol. 48:439-450.

Barry, S. R., and Gelperin, A. (1982b). Dietary choline augments blood choline and cholinergic transmission in terrestrial mollusk Limax maximus. J. Neurophysiol. 48:451-457.

Beltz, B., and Gelperin, A. (1979). An ultrastructural analysis of the salivary system of the terrestrial mollusc, Limax maximus. Tissue Cell 11:31-50.

Beltz, B., and Gelperin, A. (1980). Mechanism of peripheral modulation of the salivary burster in Limax maximus: A presumptive sensorimotor neuron. J. Neurophysiol. 44:675-686.

Bennett, M. F., and McLachlan, E. M. (1972a). An electrophysiological analysis of the storage of acetylcholine in preganglionic nerve terminals. $J$. Physiol. 221:657-668.

Bennett, M. F., and McLachlan, E. M. (1972b). An electrophysiological analysis of the synthesis of acetylcholine in preganglionic nerve terminals. J. Physiol. 221:669-682.

Birks, R., and MacIntosh, F. C. (1961). Acetylcholine metabolism by a sympathetic ganglion. Can. $J$. Biochem. Pharmacol. 39:787-827.

Ceccarelli, B., and Hurlbut, W. P. (1975). The effect of prolonged repetitive stimulation in hemicholinium in the frog neuromuscular junction. J. Physiol. 247:163-188.

Ceccarelli, B., Hurlbut, W. P., and Mauro, A. (1973). Turnover of transmitter and synaptic vesicles at the frog neuromuscular junction. J. Cell Biol. 57:499-524.

Cohen, E. L., and Wurtman, R. J. (1976). Brain acetylcholine: control by dietary choline. Science 205:1039-1040.

Collier, B. (1969). The preferential release of newly-synthesized transmitter by a sympathetic ganglion. $J$. Physiol. 205:1039-1040.

Collier, B., and Ilson, D. (1977). The effect of preganglionic nerve stimulation on the accumulation of certain analogues of choline by a sympathetic ganglion. J. Physiol. 264:489-509.

Collier, B., and Katz, H. (1974). Acetylcholine synthesis from recaptured choline by a sympathetic ganglion. J. Physiol. 238:639-655.

Eisenstadt, M. L., Treistman, S. N., and Schwartz, J. H. (1975). Metabolism of acetylcholine in the nervous system of Aplysia californica: Regional localization and characterization of choline uptake. J. Gen. Physiol. 65:275-291.

Gorio, A., Hurlbut, W. P., and Ceccarelli, B. (1978). Acetylcholine compartments in mouse diaphragm: comparison of the effects of black widow spider venom, electrical stimulation, and high concentrations of potassium. J. Cell Biol. 78:716-733.

Murrin, L. C., and Kuhar, M. J. (1976). Activation of high-affinity choline uptake in vitro by depolarizing agents. Mol. Pharmacol. 12:1082-1090.

Murrin, L. C., DeHaven, R. N., and Kuhar, M. J. (1977). On the relationship between $\left[{ }^{3} \mathrm{H}\right]$ choline uptake activation and $\left[{ }^{3} \mathrm{H}\right]$ acetylcholine release. J. Neurochem. 29:681-687.

Osborne, N. N. (1976). The uptake of ${ }^{3} \mathrm{H}$-choline by the snail (Helix pomatia) nervous tissue in vitro. $J$. Neurochem. 27:517-522.

Potter, L. T. (1970). Synthesis, storage, and release of $\left[{ }^{14} \mathrm{C}\right]$ acetylcholine in isolated rat diaphragm muscles. J. Physiol. 206:146-166. 
Prior, D. J., and Gelperin, A. (1977). Autoactive molluscan neuron: Reflex function and synaptic modulation during feeding in the terrestrial slug Limax maximus. J. Comp. Physiol. 114:217-232.

Sacchi, O., and Perri, V. (1973). Quantal mechanism of transmitter release during progressive depletion of the presynaptic store of a ganglionic synapse: The action of hemicholinium- 3 and thiamine deprivation. J. Gen. Physiol. 61:342-360.

Ulus, I. H., Hirsch, M. J., and Wurtman, R. J. (1977). Trans-synaptic induction of adrenomedullary tyrosine hydroxylase activity by choline: Evidence that choline administration can increase cholinergic transmission. Proc. Natl. Acad. Sci. 74:798-800. 